\title{
Major complications following surgical correction of spine deformity in 257 patients with cerebral palsy
}

\author{
Burt Yaszay $^{1,2}$ (C) Carrie E. Bartley ${ }^{1} \cdot$ Paul D. Sponseller $^{3} \cdot$ Mark Abel $^{4} \cdot$ Patrick J. Cahill $^{5} \cdot$ Suken A. Shah ${ }^{6}$. \\ Firoz Miyanji ${ }^{7}$. Amer F. Samdani ${ }^{7}$. Carlie Daquino ${ }^{1}$ - Peter O. Newton ${ }^{1,2}$
}

Received: 21 February 2020 / Accepted: 25 June 2020 / Published online: 27 July 2020

(c) Scoliosis Research Society 2020

\begin{abstract}
Study design Observational.

Objectives To report on the rate of major complications following spinal fusion and instrumentation to treat spinal deformity in patients with cerebral palsy $(\mathrm{CP})$.

Summary of background data Understanding the risk of major complications following the surgical treatment of spine deformities in patients with $\mathrm{CP}$ is critical.

Methods A prospectively collected, multicenter database of patients with $\mathrm{CP}$ who had surgical correction of their spinal deformity (scoliosis or kyphosis) was reviewed for all major complications. Patients with $\geq 2$ year follow-up or who died $\leq 2$ years of surgery were included. A complication was defined as major if it resulted in reoperation, re-admission to the hospital, prolongation of the hospital stay, was considered life-threatening, or resulted in residual disability. Overall complication and revision rates were calculated for the perioperative (Peri-op; occurring $\leq 90$ days postoperative) and delayed postoperative (Delayed; $>90$ days) time periods.

Results Two hundred and fifty-seven patients met inclusion. Seventy-eight (30\%) patients had a major complication, 18 (7\%) had $>1$. There were 92 (36\%) major complications; 64 (24.9\%) occurred Peri-op. The most common Peri-op complications were wound $(n=16,6.2 \%)$ and pulmonary issues $(n=28,10.9 \%)$, specifically deep infections $(n=12,4.7 \%)$ and prolonged ventilator support $(n=21,8.2 \%)$. Delayed complications $(n=28,10.9 \%)$ were primarily deep infections $(\mathrm{n}=8,3.1 \%)$ and instrumentation-related $(n=6,2.3 \%)$. There were 42 additional surgeries for an overall unplanned return to the operating room rate of $16 \%$ (Peri-op: 8.6\%, Delayed: 7.8\%). Thirty-six (14.0\%) reoperations were spine related surgeries (wound or instrumentation-related). Eleven (4.3\%) patients died between 3 months to 5.6 years postoperatively; 4 occurred $\leq 1$ year of surgery. Two deaths were directly related to the spinal deformity surgery.
\end{abstract}

Conclusion Spinal deformity surgery in CP patients with greater than 2 years of follow-up have a postoperative major complication rate of $36 \%$ with a spine-related reoperation rate of $14.0 \%$.

Level of evidence Therapeutic-IV.

Keywords Complications $\cdot$ Fusion $\cdot$ Cerebral palsy $\cdot$ Neuromuscular scoliosis $\cdot$ Deformity

Burt Yaszay

byaszay.rady@gmail.com

1 Division of Orthopedics and Scoliosis, Rady Children's Hospital, 3020 Children's Way, MC 5062, San Diego, CA 92123, USA

2 Department of Orthopedics, University of California, San Diego, CA, USA

3 Department of Orthopedics, Johns Hopkins Children's Center, Baltimore, MD, USA
4 Department of Orthopedics, University of Virginia Medical Center, Charlottesville, VA, USA

5 Department of Orthopedics, Children's Hospital of Philadelphia, Philadelphia, PA, USA

6 Nemours Alfred I. duPont Hospital for Children, Wilmington, DE, USA

7 Department of Orthopedics, British Columbia Children's Hospital, Vancouver, BC, Canada 


\section{Introduction}

Cerebral Palsy (CP) is a disorder characterized by an impairment of movement that results from a non-progressive abnormality in the developing brain. Lack of control and/or spasticity of truncal muscles frequently lead to scoliosis especially when the extent of involvement is more severe. In some cases this scoliosis and pelvic obliquity may create progressive symptoms and functional impairment that may benefit from surgical correction, typically with a spinal instrumentation and fusion from $\mathrm{T} 2$ to the pelvis. When compared to idiopathic scoliosis, surgical intervention in the $\mathrm{CP}$ population is associated with higher rates of perioperative and postoperative complications [1-3]. This is likely due to differences in co-morbidities and surgical complexity between the two populations.

Depending on the study, complication rates in patients undergoing spinal deformity surgery ranging from 18 to $65 \%$ have been reported in the literature [3-5]. The wide discrepancy in rates of complications is likely based on historical data, inclusion of other neuromuscular conditions, and differences in complication criteria. Recently, Samdani et al. reported a 39\% complication rate in 127 patients with $\mathrm{CP}$ [2]. The presence of a complication was associated with an increased length of ICU stay (7.8 days vs. 3.2).

The decision to pursue surgery in the CP patient should balance the intended outcome with the potential risk of complications. Providing accurate and up-to-date information for known complications with modern day treatment will allow for improved informed consent and better standards for reimbursement in the era of pay for performance. The purpose of this study is to report on the rate of major perioperative and delayed complications in a prospectively enrolled cohort of surgically treated spinal deformity patients with an underlying diagnosis of cerebral palsy and a minimum of 2 years follow-up after the spinal fusion procedure.

\section{Methods}

A prospectively collected (2008-2014), multicenter database of patients with $\mathrm{CP}$ who underwent spinal fusion and instrumentation to correct their spine deformity (scoliosis or kyphosis) was reviewed for all major complications. Patients with minimum 2 year follow-up or who died within 2 years of surgery were included. For inclusion into the database, patients had to be age 8-21 years at the time of surgery, have a diagnosis of CP with spinal deformity, and undergo a spinal fusion for a coronal curve $>50^{\circ}$ or a kyphotic deformity from T5-T12>70 .
A complication was defined as major if it resulted in reoperation, re-admission to the hospital, a prolongation of the initial hospital stay, was considered life-threatening, or resulted in residual disability. A standardization manual that defined each complication was provided to all participating site research investigators and coordinators. Complications were classified into 1 of 11 categories: Death, Gastrointestinal, Instrumentation, Medical, Neurologic, Pain, Pulmonary, Pseudarthrosis, Reoperation (not otherwise categorized), Surgical Site/Incision ("wound"), and Transfusion. For the full list of complications included within these categories, see Bartley et al. [1]. If more than one related complications occurred, the most severe was the category that was counted in the overall rate. A review of all reported complications was performed first by a research team independent of the surgeon, as then by a subcommittee of study group members to provide consistency and quality assurance. In addition, a secondary review of the complications was performed to confirm if a complication met the defined "major complication" criteria. Demographic and operative data for each patient was analyzed. The deaths, major complications and reoperations were analyzed for the perioperative (occurring $\leq 90$ days postoperatively) and delayed ( $>90$ days postoperatively) time periods. Patient caregiver reported outcomes, as assessed using the CPChild questionnaire and Health Utilities Index (HUI3), were evaluated preoperatively and 2 years postoperatively for the entire cohort as well as between those who experienced a complication and those who did not.

\section{Results}

\section{Demographics}

Two hundred and fifty-seven patients met the greater than 2 year follow-up inclusion criteria. The average length of follow-up was $3.3 \pm 1.6$ years (range 0.1-7.3 including the follow-up for those who died prior to 2 years postoperatively). There was a $67 \%$ follow-up rate with minimum 2 years. The average age at time of surgery was $14 \pm 3$ years. There were 135 males and 122 females. The gross motor function classification system (GMFCS) levels for the cohort were as follows: Level V: 184, Level IV: 45, Level III: 10, Level II: 5, Level I: 1, Level Unavailable: 12. One hundred and ninety $(74 \%)$ patients had profound to severe mental retardation, $176(68 \%)$ had a history of seizures, $96(37 \%)$ had a history of pneumonia, and 137 (53\%) patients required a G-tube for feeding. Scoliosis was the primary deformity in 234 patients (major curve: $86 \pm 22^{\circ}$ ) and kyphosis (T2-T12 kyphosis: $79 \pm 20^{\circ}$ ) was the primary deformity in 23 . The average coronal deformity for the entire cohort was $82 \pm 25^{\circ}$. 
The average kyphosis was $44 \pm 24^{\circ}$ from $\mathrm{T} 2$ to $\mathrm{T} 12$, and $37 \pm 23^{\circ}$ from $\mathrm{T} 5$ to $\mathrm{T} 12$. Radiographic measurements for each primary deformity, as well as for the entire cohort can be found in Table 1 .

The surgical correction procedures included the following: 227 posterior spinal fusion and instrumentation (PSF) cases, 26 PSF with an anterior release, 3 combined PSF with anterior spinal fusion/instrumentation, and 1 anterior only spinal fusion with instrumentation. The majority of patients were fused proximally between $\mathrm{T} 1$ and $\mathrm{T} 3$ (94\%; range C5-T9) and distally to the pelvis (91\%; range L2-Ilium). For all procedures combined, the average operative time was $425 \pm 174$ min (range 180-1266) and the average EBL was $1763 \pm 1287 \mathrm{cc}$ (range 150-8500), with an average of $972 \pm 904 \mathrm{cc}$ (range 0-7500) of blood transfused. The average length of hospital stay was $13 \pm 12$ days (range 3-137) and the average length of days in the ICU was $5 \pm 6$ (range $0-46$ ). All but 12 patients (95\%) were admitted to the ICU postoperatively. On average, patients received ventilator support for $2.7 \pm 4.2$ days (range $0-39$ ).

\section{Major complications}

Seventy-six (30\%) patients had a major complication, 18 (7\%) of which had 2-3 major complications. There were a total of 92 (36\%) major complications, 64 (24.9\%) occurred perioperatively (Table 2 ). The most common perioperative complications were wound healing related $(n=16,6.2 \%)$ and pulmonary issues $(n=28,10.9 \%)$, specifically deep infections $(n=12,4.7 \%)$ and prolonged ventilator support $(n=21$, $8.2 \%)$. Delayed complications $(n=28,10.9 \%)$ were primarily deep infections $(n=8,3.1 \%)$ and instrumentation related $(n=6,2.3 \%)$. On average, major complications occurred 5.5 months postoperatively (range immediate to 5.5 years). There was no difference in the distribution of complication based on GMFCS level: Level V: Y-31\% vs N-69\%, Level IV: Y-24\% vs N-76\%, Level III: Y-40\% vs N-60\%, Level II: Y-20\% vs N-80\%, Level I: Y-0\% vs N-100\%, Level Unavailable: $\mathrm{Y}-25 \%$ vs N-75\%; $p=0.8$.

There were 42 additional surgeries for an overall unplanned return to the operating room rate of $16 \%$ (Periop: $8.6 \%$, Delayed: $7.8 \%)$. Thirty-six (14.0\%) surgeries were spine related, with the majority being wound $(8.7 \%)$ or instrumentation related (2.7\%). Table 3 summarizes the indications for the spine-related revision procedures. The single most frequent indication for reoperation was a deep infection (6.6\%). Eleven (4.2\%) patients died between 3 months to 5.6 years postoperatively, with 4 occurring within 1 year of surgery. Two deaths were directly related to the spinal deformity surgery and included in the major complication rate. The first death related to the spinal deformity surgery occurred 3 months postoperatively and involved a cerebral infarction due to acute hydrocephalus and E. coli meningitis. The second related death followed a viral infection 2 months after being treated for a wound infection. The causes of the non-spine surgery related deaths were varied: gastrointestinal related (3), respiratory related (2), seizure (1), and unknown (3).

\section{Caregiver reported outcomes}

Significant improvements were seen from preoperative to 2 years postoperative for the entire cohort in all CPChild domains and total score: Activities of daily living ( $39 \pm 16$ to $45 \pm 17, p<0.001)$, Transferring and Mobility $(34 \pm 17$ to $45 \pm 17, p<0.001)$, Comfort and Emotions $(75 \pm 21$ to $82 \pm 18, p<0.001)$, Communications and Social Interactions $(54 \pm 30$ to $57 \pm 28, p=0.048)$, Health $(56 \pm 20$ to $62 \pm 20, p<0.001)$, Overall Quality of Life $(62 \pm 24$ to $71 \pm 23, p<0.001)$, and Total Score $(51 \pm 15$ to $58 \pm 15$, $p<0.001)$. No significant difference was observed in HUI Overall Utility Score for the entire cohort from preoperative $(-0.08 \pm 0.2)$ to 2 years $(-0.06 \pm 0.2)(p=0.2)$.

The change from preoperative to 2 years postoperative in all CPChild domains was not significantly different based on whether a major complication occurred or not (Table 4). However, the complication group had a HUI score that worsened slightly $(-0.08$ to -0.10$)$, whereas the no complication group showed a modest improvement $(-0.08$ to -0.03$)$ $p=0.035$.

\section{Discussion}

Surgery for scoliosis in patients with $\mathrm{CP}$ can come with high risks due to the comorbidities associated with this condition. Having current and accurate information regarding major complications following spinal fusion and instrumentation for significant scoliosis and/or kyphosis in the CP patient is important in weighing the costs against the benefits when

Table 1 Radiographic data

\begin{tabular}{lllll}
\hline Primary deformity & $\begin{array}{l}\text { Major coronal curve } \\
\text { magnitude }\left(^{\circ}\right)\end{array}$ & $\begin{array}{l}\text { T2-T12 kkypho- } \\
\text { sis }\left(^{\circ}\right)\end{array}$ & $\begin{array}{l}\text { T5-T12 kypho- } \\
\text { sis }\left(^{\circ}\right)\end{array}$ & Pelvic obliquity $\left(^{\circ}\right)$ \\
\hline Scoliosis & $86 \pm 22$ & $40 \pm 21$ & $34 \pm 20$ & $29 \pm 15$ \\
Kyphosis & $47 \pm 21$ & $79 \pm 20$ & $70 \pm 20$ & $17 \pm 14$ \\
Total cohort & $82 \pm 25$ & $44 \pm 24$ & $37 \pm 23$ & $28 \pm 16$ \\
\hline
\end{tabular}


Table 2 Major complications by categories

\begin{tabular}{|c|c|c|c|c|c|}
\hline Complication type & Total & Peri-operative & Delayed & $\begin{array}{l}\text { Additional } \\
\text { surgeries (all } \\
\text { causes) }\end{array}$ & $\begin{array}{l}\text { Spine-related } \\
\text { reoperations }\end{array}$ \\
\hline Gastrointestinal & $6(2.3 \%)$ & $4(1.6 \%)$ & $2(0.8 \%)$ & $3(1.2 \%)$ & $0(0 \%)$ \\
\hline $\begin{array}{l}\text { Difficulty swallowing ( } 1 \text { with increased abdominal distention and } \\
\text { silent aspirations) }\end{array}$ & 3 & 2 & 1 & 2 & 0 \\
\hline Superior mesenteric artery syndrome & 2 & 1 & 1 & & \\
\hline Abdominal distention and/or leakage at gastrostomy tube site & 1 & 1 & 0 & 1 & 0 \\
\hline Surgery related death & $2(0.8 \%)^{*}$ & $1(0.4 \%)$ & $1(0.4 \%)$ & $0(0 \%)$ & $0(0 \%)$ \\
\hline Instrumentation & $7(2.7 \%)$ & $1(0.4 \%)$ & $6(2.3 \%)$ & $7(2.7 \%)$ & $7(2.7 \%)$ \\
\hline Loss of connection between implants & & & 2 & 2 & 2 \\
\hline Loss of fixation to bone & & & 2 & 2 & 2 \\
\hline Prominent Hardware & & 1 & 1 & 2 & 2 \\
\hline Broken rod & & & 1 & 1 & 1 \\
\hline Medical & $15(5.8 \%)$ & $11(4.3 \%)$ & $4(1.6 \%)$ & $4(1.6 \%)$ & $2(0.8 \%)$ \\
\hline $\begin{array}{l}\text { Hypotension ( } 1 \text { resulting in renal failure, } 1 \text { with late onset shock } \\
\text { presumably due to adrenal insufficiency) }\end{array}$ & & 3 & 2 & & \\
\hline Deep vein thrombosis & & 2 & 1 & & \\
\hline Broken central line wire & & 1 & & 1 & \\
\hline Dural tear/leak & & & 1 & 1 & 1 \\
\hline Hematuria intraoperatively & & 1 & & 1 & 1 \\
\hline Inotrope resistant shock and presumed adrenal insufficiency & & 1 & & & \\
\hline Myocardial infarction & & 1 & & & \\
\hline $\begin{array}{l}\text { Peritonitis, acute vascular insufficiency of intestine, abscess, bowel } \\
\text { necrosis and perforation }\end{array}$ & & 1 & & 1 & \\
\hline Urinary tract infection requiring hospital readmission & & 1 & & & \\
\hline Neurologic & $1(0.4 \%)$ & $1(0.4 \%)$ & $0(0 \%)$ & $0(0 \%)$ & $0(0 \%)$ \\
\hline Bladder urinary retention & 1 & & & & \\
\hline Pseudarthrosis & $2(0.8 \%)$ & $0(0 \%)$ & $2(0.8 \%)$ & $2(0.8 \%)$ & $2(0.8 \%)$ \\
\hline Pseudarthrosis (only) requiring revision & & & 1 & 1 & 1 \\
\hline Pseudarthrosis with broken rod, requiring revision & & & 1 & 1 & 1 \\
\hline Pulmonary & $31(12.1 \%)$ & $28(10.9 \%)$ & $3(1.2 \%)$ & $1(0.4 \%)$ & $0(0 \%)$ \\
\hline Prolonged ventilator support (failed initial extubation) & & 21 & & & \\
\hline Systemic Inflammatory response syndrome & & 4 & 1 & & \\
\hline Pneumonia & & 2 & 2 & 1 & \\
\hline Pneumothorax requiring chest tube & & 1 & & & \\
\hline Reoperation & $3(1.2 \%)$ & $1(0.4 \%)$ & $1(0.4 \%)$ & $3(1.2 \%)$ & $3(1.2 \%)$ \\
\hline Proximal junctional kyphosis & & 1 & 1 & 2 & 2 \\
\hline Unplanned staged procedure due to intraoperative blood loss & & 1 & & 1 & 1 \\
\hline Wound & $25(9.7 \%)$ & $16(6.2 \%)$ & $9(3.5 \%)$ & $22(8.6 \%)$ & $22(8.6 \%)$ \\
\hline Infection-deep & & 12 & 8 & 17 & 17 \\
\hline Dehiscence & & 1 & 1 & 2 & 2 \\
\hline Infection-superficial & & 2 & & 2 & 2 \\
\hline Retained drain & & 1 & & 1 & 1 \\
\hline Total & $92(35.8 \%)$ & $64(24.9 \%)$ & $28(10.9 \%)$ & $42(16.3 \%)$ & $36(14.0 \%)$ \\
\hline
\end{tabular}

*Nine additional deaths unrelated to the spine surgeries were reported during the follow-up period: gastrointestinal related (2), respiratory related (2), seizure (1), and unknown (3)

educating a family on whether to pursue surgery for patients in this population. Therefore, the current study reports on the major complications, both perioperative and delayed, in a large prospectively collected series of surgically treated patients with $\mathrm{CP}$ and spinal deformity.

This study is not without limitations. As these patients have frequent comorbidities, it is challenging to identify 
Table 3 Spine related reoperations

\begin{tabular}{llll}
\hline & \multicolumn{3}{l}{ Spine-related reoperations } \\
\cline { 2 - 4 } & Total & Perioperative & Delayed \\
\hline Gastrointestinal & $0(0 \%)$ & $0(0 \%)$ & $0(0 \%)$ \\
Death & $0(0 \%)$ & $0(0 \%)$ & $0(0 \%)$ \\
Instrumentation & $7(2.7 \%)$ & $1(0.4 \%)$ & $6(2.3 \%)$ \\
Broken rod & $1(0.4 \%)$ & $0(0 \%)$ & $1(0.4 \%)$ \\
Loss of connection between implants & $2(0.8 \%)$ & $0(0 \%)$ & $2(0.8 \%)$ \\
Loss of fixation to bone & $1(0.4 \%)$ & $0(0 \%)$ & $1(0.4 \%)$ \\
Promiment hardware & $2(0.8 \%)$ & $1(0.4 \%)$ & $1(0.4 \%)$ \\
Other & $1(0.4 \%)$ & $0(0 \%)$ & $1(0.4 \%)$ \\
Medical & $2(0.8 \%)$ & $1(0.4 \%)$ & $1(0.4 \%)$ \\
Dural tear/leak & $1(0.4 \%)$ & $0(0 \%)$ & $1(0.4 \%)$ \\
Other & $1(0.4 \%)$ & $1(0.4 \%)$ & $0(0 \%)$ \\
Neurologic & $0(0 \%)$ & $0(0 \%)$ & $0(0 \%)$ \\
Pseudarthrosis & $2(0.8 \%)$ & $0(0 \%)$ & $2(0.8 \%)$ \\
Pseudarthrosis—only & $1(0.4 \%)$ & $0(0 \%)$ & $1(0.4 \%)$ \\
Pseudarthrosis with broken rod & $1(0.4 \%)$ & $0(0 \%)$ & $1(0.4 \%)$ \\
Pulmonary & $0(0 \%)$ & $0(0 \%)$ & $0(0 \%)$ \\
Reoperation (PJK, unplanned staged procedure) & $3(1.2 \%)$ & $2(0.8 \%)$ & $1(0.4 \%)$ \\
Deep Infection & $17(6.6 \%)$ & $9(3.5 \%)$ & $8(3.1 \%)$ \\
Wound-other (Superficial infection, dehiscence, other) & $5(1.9 \%)$ & $4(1.6 \%)$ & $1(0.4 \%)$ \\
Total & $36(14.0 \%)$ & $15(5.8 \%)$ & $21(8.3 \%)$ \\
\hline
\end{tabular}

Table 4 Comparison of changes in preoperative to postoperative patient/caregiver reported outcomes based on whether patients experienced a complication or not

\begin{tabular}{|c|c|c|c|c|c|}
\hline & \multicolumn{2}{|l|}{ Preoperative } & \multicolumn{2}{|c|}{2 years postoperative } & \multirow{2}{*}{$\begin{array}{l}\text { Change from pre to } 2 \text { years } \\
\text { based on complication group } \\
p \text { value }\end{array}$} \\
\hline & Yes complication & No complication & Yes complication & No complication & \\
\hline \multicolumn{6}{|l|}{ CPCHILD } \\
\hline $\begin{array}{l}\text { Personal care-activities of daily } \\
\text { living }\end{array}$ & $38 \pm 15$ & $40 \pm 16$ & $42 \pm 18$ & $46 \pm 17$ & 0.3 \\
\hline $\begin{array}{l}\text { Positioning, transferring and mobil- } \\
\text { ity }\end{array}$ & $34 \pm 16$ & $34 \pm 18$ & $42 \pm 19$ & $46 \pm 17$ & 0.2 \\
\hline Comfort and emotions & $71 \pm 21$ & $76 \pm 21$ & $78 \pm 22$ & $84 \pm 16$ & 0.9 \\
\hline $\begin{array}{l}\text { Communications and social interac- } \\
\text { tions }\end{array}$ & $53 \pm 31$ & $54 \pm 29$ & $52 \pm 29$ & $58 \pm 28$ & 0.2 \\
\hline Health & $54 \pm 20$ & $57 \pm 20$ & $59 \pm 19$ & $63 \pm 20$ & 0.6 \\
\hline Overall quality of life & $59 \pm 25$ & $64 \pm 23$ & $66 \pm 26$ & $74 \pm 22$ & 0.7 \\
\hline Total score & $50 \pm 16$ & $52 \pm 14$ & $54 \pm 17$ & $59 \pm 14$ & 0.1 \\
\hline \multicolumn{6}{|l|}{ HUI3 } \\
\hline Overall utility score & $-0.08 \pm 0.28$ & $-0.08 \pm 0.23$ & $-0.11 \pm 0.25$ & $-0.03 \pm 0.24$ & $0.035^{*}$ \\
\hline
\end{tabular}

*Statistically significance difference based on repeated measures ANOVA

the relative contribution of the surgery versus the patient's overall health to any given postoperative complication. Whereas some major complications are clearly associated with the surgery (e.g., broken rod), others may be partially attributable to a pre-existing condition (e.g., failed extubation in a patient with limited respiratory function). Additionally, this study was a multicenter study with each site responsible for self-reporting postoperative complications. However, to help reduce the variability in reporting, a standardization manual was provided to all sites and a quality assurance review was conducted by a research team independent of the surgeon, as well as by a subcommittee of study group members to provide consistency and quality assurance. Finally, all complications were again 
reviewed by the authors to confirm the "major" complication categorization.

Of the 257 patients, 76 patients (30\%) experienced 92 major complications giving an overall rate of $36 \%$ (25\% perioperative), with a reoperation rate of $16 \%$. There was a $14 \%$ reoperation rate for spine-related revisions. The majority of all complications were pulmonary $(12.1 \%)$, wound $(9.7 \%)$, or medical $(5.8 \%)$ related.

The risk of pulmonary problems in neuromuscular patients following spinal surgery is well known and includes respiratory failure, aspiration, pneumonia, pneumothorax, or pleural effusion [2, 6, 7]. Rates between 17 and 50\% have been reported in the literature [6-9]. Scoliosis surgery has been shown to produce a transient decrease in vital capacity in all patients [10]. Therefore, neuromuscular patients with pre-existing pulmonary compromise should be identified before surgery to optimize lung function. These patients will be at particular risk for requiring prolonged mechanical ventilation. Aggressive management by the intensive care unit with protocols for early extubation and the use of non-invasive ventilation (BIPAP and NCPAP) have demonstrated benefits in the prevention of respiratory failure $[11,12]$. Pre-operative assessment by pulmonology to optimize pulmonary function before proceeding with surgery may also help minimize some of this risk.

The second most common complication reported in our study was wound related $(9.7 \%)$. This is significantly higher than the published $1-2 \%$ rate seen in the AIS population $[1,13-16]$. They were primarily deep wound infections but also included superficial infections, dehiscence, seroma, hematoma, and prolonged drainage; all required a reoperation. While the majority occurred in the perioperative period (6.2\%), a significant portion was delayed (3.5\%). Our rate of wound complications was similar to those already reported in the literature for CP scoliosis $[6,17,18]$. Sponseller et al. reported a $10 \%$ infection rate in a retrospective review of $157 \mathrm{CP}$ patients treated for scoliosis [19]. They found higher preoperative white blood cell count and the use of unit rods to be risk factors for the development of a postoperative infection.

Medical complications occurred in $5.8 \%$ of patients and represent a diverse group of problems. They include: hypotension or shock, myocardial infarction, urinary tract infection, deep vein thrombosis and others. While difficult to analyze individually, grouped together they demonstrate the complexity of the postoperative care of the $\mathrm{CP}$ patient. Not routinely reported in the literature, major medical complications in the AIS population are exceedingly rare with a reported incidence of $0.06 \%$ in a recent publication ${ }^{1}$. Appropriate medical management by the ICU or medical specialists may be needed and in some cases outweigh the postoperative surgical management.
The most concerning complication reported in this study is the mortality following surgery. There were 11 deaths that occurred after the time of spine surgery, 4 of which occurred within 1 year. Only 2 of the deaths were known to be directly related to the spine surgery. One occurred 3 months postoperatively and included cerebral infarction due to acute hydrocephalus and E. coli meningitis. The other death was related to an infection 2 months after being treated for a wound infection. Very few reports exist on the mortality following spinal deformity surgery. Barsdorf et al. reported a $1.6 \%$ in-hospital mortality rate for pediatric patients undergoing correction of neuromuscular spinal deformity [20]. This rate, however, was not specific to the $\mathrm{CP}$ population. Tsirikos et al. reported a $1 \%$ perioperative mortality rate following spinal surgery in patients with $\mathrm{CP}$ [21]. This is similar to our rate of $0.8 \%$ that we found directly related to surgical treatment. The other important issue our findings open to consideration is the general survivorship of the $\mathrm{CP}$ patient that undergoes scoliosis. Approximately $4 \%$ of the 257 patients analyzed died following their surgery timing of which ranged from the perioperative period to 5 years postoperative. This was significantly lower than the $28 \%$ mortality rate Sitoula et al. found [22]. Their patients were younger at the time of surgery with a mean age of 8.3 years suggesting a more severe patient population.

\section{Conclusion}

Spinal surgery for CP can have significant major complications. When preparing patients and their families, having an accurate understanding of complication rates following spinal fusion and instrumentation for $\mathrm{CP}$ is of great importance. In addition, many of these risks may be reduced by optimizing patients' overall health [23]. While a formal process has not been employed by this multicenter group, many centers will refer patients for pulmonary, nutritional and anesthetic assessment before any procedure is undertaken. In some cases, the risks of complications may be too extreme to consider pursuing a surgical intervention. With a major complication rate of $36 \%$ and a spine-related reoperation rate of $14 \%$, future studies will be needed to better understand the risk and methods to mitigate these risks.

\section{Key Points}

- In patients with CP undergoing spinal fusion and instrumentation for a spinal deformity, there was a major perioperative complication rate of $36 \%$ with a spine-related reoperation rate of $14 \%$.

- Within the perioperative period, the major complication rate was $25 \%$ and the reoperation rate was $8.6 \%$. 
The majority of these complications were pulmonary $(11 \%)$, wound $(6 \%)$, or medical $(4 \%)$ related.

- The rate of delayed major complications was $11 \%$, which were primarily deep infections (3\%) and instrumentation-related (2\%).

- Spinal surgery for CP can have significant major complications and it is of great importance to have an accurate understanding of the complication rates when preparing patients and their families for the procedure.

\begin{abstract}
Acknowledgements Harms Study Group Investigators: Aaron Buckland, MD; New York University. Amer Samdani, MD; Shriners Hospitals for Children-Philadelphia. Amit Jain, MD; Johns Hopkins Hospital. Baron Lonner, MD; Mount Sinai Hospital. Benjamin Roye, MD; Columbia University. Burt Yaszay, MD; Rady Children's Hospital. Chris Reilly, MD; BC Children's Hospital. Daniel Hedequist, MD; Boston Children's Hospital. Daniel Sucato, MD; Texas Scottish Rite Hospital. David Clements, MD; Cooper Bone \& Joint Institute New Jersey. Firoz Miyanji, MD; BC Children's Hospital. Harry Shufflebarger, MD; Nicklaus Children's Hospital. Jack Flynn, MD; Children's Hospital of Philadelphia. Jahangir Asghar, MD; Cantor Spine Institute. Jean Marc Mac Thiong, MD; CHU Sainte-Justine. Joshua Pahys, MD; Shriners Hospitals for Children-Philadelphia. Juergen Harms, MD; Klinikum Karlsbad-Langensteinbach, Karlsbad. Keith Bachmann, MD; University of Virginia. Larry Lenke, MD; Columbia University. Mark Abel, MD; University of Virginia. Michael Glotzbecker, MD; Boston Children's Hospital. Michael Kelly, MD; Washington University. Michael Vitale, MD; Columbia University. Michelle Marks, PT, MA; Setting Scoliosis Straight Foundation. Munish Gupta, MD; Washington University. Nicholas Fletcher, MD; Emory University. Patrick Cahill, MD; Children's Hospital of Philadelphia. Paul Sponseller, MD; Johns Hopkins Hospital. Peter Gabos, MD: Nemours/Alfred I. duPont Hospital for Children. Peter Newton, MD; Rady Children's Hospital. Peter Sturm, MD; Cincinnati Children's Hospital. Randal Betz, MD; Institute for Spine \& Scoliosiscba. Ron Lehman, MD; Columbia University. Stefan Parent, MD: CHU Sainte-Justine. Stephen George, MD; Nicklaus Children's Hospital. Steven Hwang, MD; Shriners Hospitals for Children-Philadelphia. Suken Shah, MD; Nemours/Alfred I. duPont Hospital for Children. Tom Errico, MD; Nicklaus Children's Hospital. Vidyadhar Upasani, MD; Rady Children's Hospital
\end{abstract}

Author contributions Conception or design of the work; or Acquisition, analysis, or interpretation of data for the work: BY, CEB, PDS, MA, PJC, SAS, FM, AFS, CD, PON; Drafting or critically revising the work: BY, CEB, PDS, MA, PJC, SAS, FM, AFS, CD, PON; Final approval of the version to be published: BY, CEB, PDS, MA, PJC, SAS, FM, AFS, CD, PON.

Funding This study was supported in part by grants to the Setting Scoliosis Straight Foundation from DePuy Synthes Spine, EOS imaging, K2M, Medtronic, NuVasive and Zimmer Biomet in support of Harms Study Group research.

\section{Compliance with ethical standards}

Ethics approval This study has been approved by the IRB.

\section{References}

1. Bartley CE, Yaszay B, Bastrom TP et al (2017) Perioperative and delayed major complications following surgical treatment of adolescent idiopathic scoliosis. J Bone Joint Surg Am 99:1206-1212

2. Samdani AF, Belin EJ, Bennett JT et al (2016) Major perioperative complications after spine surgery in patients with cerebral palsy: assessment of risk factors. Eur Spine J 25:795-800

3. Sharma S, Wu C, Andersen T et al (2013) Prevalence of complications in neuromuscular scoliosis surgery: a literature meta-analysis from the past 15 years. Eur Spine J 22:1230-1249

4. Master DL, Son-Hing JP, Poe-Kochert C et al (2011) Risk factors for major complications after surgery for neuromuscular scoliosis. Spine (Phila Pa 1976) 36:564-571

5. Rumalla K, Yarbrough CK, Pugely AJ et al (2016) Spinal fusion for pediatric neuromuscular scoliosis: national trends, complications, and in-hospital outcomes. J Neurosurg Spine 25:500-508

6. Modi HN, Suh SW, Yang JH et al (2009) Surgical complications in neuromuscular scoliosis operated with posterior- only approach using pedicle screw fixation. Scoliosis 4:11

7. Mohamad F, Parent S, Pawelek J et al (2007) Perioperative complications after surgical correction in neuromuscular scoliosis. J Pediatr Orthop 27:392-397

8. Miyanji F, Nasto LA, Sponseller PD et al (2018) Assessing the risk-benefit ratio of scoliosis surgery in cerebral palsy: surgery is worth it. J Bone Joint Surg Am 100:556-563

9. Toovey R, Harvey A, Johnson M et al (2017) Outcomes after scoliosis surgery for children with cerebral palsy: a systematic review. Dev Med Child Neurol 59:690-698

10. Yuan N, Fraire JA, Margetis MM et al (2005) The effect of scoliosis surgery on lung function in the immediate postoperative period. Spine (Phila Pa 1976) 30:2182-2185

11. Ornico SR, Lobo SM, Sanches HS et al (2013) Noninvasive ventilation immediately after extubation improves weaning outcome after acute respiratory failure: a randomized controlled trial. Crit Care 17:R39

12. Burns KE, Adhikari NK, Keenan SP et al (2009) Use of non-invasive ventilation to wean critically ill adults off invasive ventilation: meta-analysis and systematic review. BMJ 338:b1574

13. Marks MC, Newton PO, Bastrom TP et al (2013) Surgical site infection in adolescent idiopathic scoliosis surgery. Spine Deform $1: 352-358$

14. Lamberet A, Violas P, Buffet-Bataillon S et al (2018) Postoperative spinal implant infections in children: risk factors, characteristics and outcome. Pediatr Infect Dis J 37:511-513

15. Kamath VH, Cheung JP, Mak KC et al (2016) Antimicrobial prophylaxis to prevent surgical site infection in adolescent idiopathic scoliosis patients undergoing posterior spinal fusion: 2 doses versus antibiotics till drain removal. Eur Spine $\mathbf{J}$ 25:3242-3248

16. Webb ML, Lukasiewicz AM, Samuel AM et al (2015) Overall Similar Infection Rates Reported in the Physician-reported Scoliosis Research Society Database and the Chart-abstracted American College of Surgeons National Surgical Quality Improvement Program Database. Spine (Phila Pa 1976) 40:1431-1435

17. Aleissa S, Parsons D, Grant J et al (2011) Deep wound infection following pediatric scoliosis surgery: incidence and analysis of risk factors. Can J Surg 54:263-269

18. Szoke G, Lipton G, Miller F et al (1998) Wound infection after spinal fusion in children with cerebral palsy. J Pediatr Orthop 18:727-733

19. Sponseller PD, Shah SA, Abel MF et al (2010) Infection rate after spine surgery in cerebral palsy is high and impairs results: multicenter analysis of risk factors and treatment. Clin Orthop Relat Res 468:711-716 
20. Barsdorf AI, Sproule DM, Kaufmann P (2010) Scoliosis surgery in children with neuromuscular disease: findings from the US National Inpatient Sample, 1997 to 2003. Arch Neurol 67:231-235

21. Tsirikos AI, Lipton G, Chang WN et al (2008) Surgical correction of scoliosis in pediatric patients with cerebral palsy using the unit rod instrumentation. Spine (Phila Pa 1976) 33:1133-1140

22. Sitoula P, Holmes L Jr, Sees J et al (2016) The long-term outcome of early spine fusion for scoliosis in children with cerebral palsy. Clin Spine Surg 29:E406-E412
23. Halawi MJ, Lark RK, Fitch RD (2015) Neuromuscular scoliosis: current concepts. Orthopedics 38:e452-e456

Publisher's Note Springer Nature remains neutral with regard to jurisdictional claims in published maps and institutional affiliations 